\title{
Evaluation of three cycles of full-sib reciprocal recurrent selection in two maize populations
}

from the Northeast of Spain

3

4 Javier Peña-Asín ${ }^{1}$, Ángel Álvarez ${ }^{1}$, Amando Ordás 2*, Bernardo Ordás ${ }^{2}$

5

6

7

8

9

* Corresponding author: phone: (+34) 976 716105, fax: (+34) 976716 145, e-mail:

11

12

13 
ABSTRACT

In Europe a heterotic pattern commonly used in maize breeding is "American Dent× European Flint". Maize breeding programs generally use only a small portion of the useful genetic variability present in the local open-pollinated varieties which, otherwise, have a poor performance that hampers their use. Two maize composites, EZS33 formed by open-pollinated flint varieties from dry or Mediterranean Spain, and EZS34 from USA dent populations, were developed in Zaragoza (Spain). Both were subjected to three cycles of full-sib reciprocal recurrent selection (RRS) for yield. The objective of our study was to evaluate after three cycles of selection the effect of RRS. The selection significantly increased yield in the population crosses (3.0\% per cycle) and in the crosses of the populations with testers of different origin. The correlated responses for the population crosses in other agronomic traits like flowering and early vigor were in the desired direction, but plant height was reduced. We propose that stover yield or related traits could be included in selection programs as selection criteria to prevent their decline. The adapted population increased the frequency of favorable alleles for yield, but the inbreeding depression counteracted their effect on the mean. RRS had a positive effect on other traits. According to our data, RRS can be useful to develop improved populations from which it would be possible to develop lines with improved both specific and general combining ability with different heterotic groups. We conclude that the heterotic pattern "Mediterranean

68 Spain $x$ US Dent" is potentially very useful for maize breeding for adaptation to Mediterranean 69 conditions and an interesting source of cultivars for low-input agriculture.

Keywords: Selection, maize, combining ability, breeding, reciprocal recurrent, Zea mays L.

\section{Abbreviations:}




\section{Introduction}

Maize (Zea mays L.) is the highest tonnage cereal crop worldwide with a production of about 819 million $\mathrm{Mg}$, followed by paddy rice with 682 million $\mathrm{Mg}$, and wheat with 679 million $\mathrm{Mg}$ (FAO, 2012). Single-cross hybrids are the predominant type of variety grown in the developed world and other areas.

Inbred lines were obtained from open pollinated varieties at the beginning of maize breeding, but after that initial period, inbreds were and are nowadays mainly obtained from populations generated by crossing elite inbred lines (Mikel, 2011). Two points are relevant regarding the genetic variability of the current elite inbred lines. First, only a small proportion of the genetic variation of the original open-pollinated varieties is used (Ho et al., 2005; Reif et al., 2005), and second, the recycling of elite inbreds is the cause that many of them have become genetically related (Mikel and Dudley, 2006; Mikel, 2011). A low genetic variability reduces the expected rate of genetic improvement (Yu and Bernardo, 2004) and increases the susceptibility to stresses (Reif et al., 2010).

The term heterotic pattern refers to a specific pair of two heterotic groups, which express high heterosis in their cross (Reif et al., 2005). The concept of heterotic pattern is widely used in maize breeding because helps to elect parents of crosses for line development and to choose testers for evaluating new hybrids (Reif et al., 2005). In Europe a successful heterotic pattern is "American Dent $\times$ European Flint" (Ordás, 1991). American cultivars can be useful sources of favorable alleles for yield, while European open-pollinated cultivars contain genes for adaptation to specific environments (Malvar et al., 2004; Revilla et al., 2006). Within the pattern "American Dent $\times$ European Flint", the crossing between Reid germplasm or derivates from the US Corn Belt with germplasm from dry or Mediterranean Spain has resulted in a large amount of heterosis (Garay et al., 1996a). Other related heterotic combinations that have, alternatively been proposed for Europe are "Lancaster(another US Corn Belt dent variety) × Spain varieties", "Reid x Argentinean Flint", and "Reid × varieties from wet or Atlantic Spain" (Soengas et al., 2003). In addition, the varieties of dry Spain have been also found to produce large heterosis with the varieties of wet Spain (Ordás, 1991).

In general, using a wide range of germplasm sources seems to be necessary for sustaining longterm breeding progress in maize and for avoiding an increase in the susceptibility to stresses (Reif et al., 2010). Exotic or adapted, but non improved, germplasm can be used to increase the genetic base of maize breeding germplasm (Romay et al., 2011). The adapted, non-improved germplasm, needs to be improved before it can be included in hybrid breeding programs because of its poor agronomic performance, particularly low yield and high lodging.

With the aim of increasing the genetic base of the germplasm used in maize breeding, two composites of populations have been developed in the Aula Dei Experimental Station, Zaragoza (Spain).These composites follow the heterotic pattern "Reid x Dry Spain". The dry Spain varieties have a special interest for increasing genetic variability because they are very variable and a source of favorable alleles for adaptation to Mediterranean climatic conditions (Garay et al., 1996b).

The composites were subjected to three cycles of $S_{1}$ progeny intrapopulation recurrent selection for grain yield (Alvarez et al., 1993). Garay et al. (1996b) confirmed that both composites showed increased grain yield and good response to selection. After that, the composites (named EZS33 and EZS34) were subjected to three cycles of full-sib reciprocal recurrent selection (RRS) for yield. RRS is a long-term breeding procedure designed to improve population crosses while 
maintaining genetic variability for continued selection (Hallauer and Eberhart, 1970). RRS also enhances the performance of hybrids obtained from lines developed from the succeeding cycles of selection (Betrán and Hallauer, 1996). Thus, both general and specific combining abilities are exploited by this breeding method. RRS has been shown very effective to improve the cross of two divergent US (Eyherabide and Hallauer, 1991; Keeratinijakal and Lamkey, 1993) or two divergent European (Romay et al., 2011) populations, but this procedure has not been evaluated for populations that follow the "American Dent $\times$ European Flint" heterotic pattern. Keeratinijakal and Lamkey (1993) showed that RRS improves the testcrosses of the reciprocal populations using two lines, one derived from the RRS program and another from a different heterotic group. Thus, RRS could be useful for improving germplasm sources, not only for the extraction of inbred lines with specific combining ability, but also for the extraction of lines with a wide general combining ability.

The objective of our study was to evaluate in populations from the "American Dent $\times$ European Flint" heterotic pattern, the effect of RRS on: (a) the direct and correlated responses in the populations and the interpopulation crosses (b) the inbreeding of the populations and the heterosis between them, and (c) on the crosses of the populations with germplasm from different origin.

\section{Materials and methods}

\section{Plant Materials}

Starting in1983 two composites were developed in Zaragoza (Spain). EZS1 was formed by intercrossing flint populations from dry Spain and EZS2 by intercrossing North American dent populations with a predominance of Reid germplasm (Garay et al., 1996a). Preliminary results indicated that superior hybrids might be developed from the cross between these composites (Alvarez et al., 1993). As the initial yields of both composites were low, they were separately subjected to $S_{1}$ progeny recurrent selection for three cycles. Cycles 0, 1, 2, and 3 of EZS1 and EZS2 have been previously evaluated for their response (Garay et al., 1996a), as well as to determine their ability to combine (Garay et al., 1996b). Later, EZS1C3 and EZS2C3 were renamed to EZS33C0 and EZS34C0, respectively, and both populations were submitted to three cycles of full-sib reciprocal recurrent selection for grain yield (figure 1).The full-sib reciprocal recurrent selection breeding program started in 1995. EZS33C0 and EZS34C0 were selfpollinated to obtain $S_{1}$ progenies (about 150 plants from each population). In 1996, $100 S_{1}$ families from EZS33C0 were randomly crossed to $100 \mathrm{~S}_{1}$ families from EZS34C0 and the $\mathrm{S}_{1} \times \mathrm{S}_{1}$ crosses were evaluated in 1997. The $100 S_{1}$ families from each composite were also selfpollinated to obtain $S_{2}$ progenies. In each population the $10 S_{2}$ families derived from the $10 S_{1}$ families with the highest yield in crosses were recombined in 1998 to generate the first cycle of selection [EZS33(FR)C1 and EZS34(FR)C1]. This methodology was also used to obtain the second cycle [EZS33(FR)C2 and EZS34(FR)C2] in 2003 and the third cycle [EZS33(FR)C3 and EZS34(FR)C3] in 2007.

In 2008 seeds from all populations(EZS33C0, EZS34C0, EZS33(FR)C1, EZS34(FR)C1, EZS33(FR)C2, EZS34(FR)C2, EZS33(FR)C3, and EZS34(FR)C3 were multiplied and the 28 possible crosses between the 8 populations were made. Additionally, the four cycles of each population (C0, C1, C2 and C3) were testcrossed to two inbred lines to know the effect of RRS on the crosses of the populations with other germplasm. EZS33 (the flint composite from dry Spain) and its cycles of selection were crossed to B93 (a Lancaster inbred) and to EP42 (a flint inbred derived from a wet Spain's population). EZS34 (the dent Reid composite) and its cycles 


\section{Evaluation trials}

The populations (8), the crosses between them (28), the testcrosses (16), and four hybrid checks were tested for two years (2009 and 2010) at three locations in Aragón (Spain) which are representative of dry areas: Montañana $\left(41^{\circ} 44^{\prime} \mathrm{N}, 0^{\circ} 47^{\prime} \mathrm{O}, 243\right.$ masl), Torres de Alcanadre (42은 $04^{\prime} \mathrm{N}, 0^{\circ} 09^{\prime} \mathrm{O}, 389$ masl), and Zuera $\left(41^{\circ} 45^{\prime} \mathrm{N}, 0^{\circ} 47^{\prime} \mathrm{O}, 325\right.$ masl). The total number of environments was finally five because the evaluation in Zuera was carried out only in 2010.The experimental design for all trials was a $7 \times 8$ triple lattice. However, for conciseness, we report here only the data of populations per se, interpopulation crosses $(\mathrm{C} 0 \times \mathrm{C} 0, \mathrm{C} 1 \times \mathrm{C} 1, \mathrm{C} 2 \times \mathrm{C} 2, \mathrm{C} 3 \times \mathrm{C} 3)$, the crosses to the initial cycle $(\mathrm{C} 0 \times \mathrm{C} 1, \mathrm{C} 0 \times \mathrm{C} 2, \mathrm{C} 0 \times \mathrm{C} 3)$, the testcrosses, and the hybrid checks (Table 1). The trials were irrigated throughout the growing seasons. Management, fertilization, pest, and weed control were carried out according to local practices, with the trials being machine planted. Each experimental plot consisted of two rows spaced $0.75 \mathrm{~m}$ apart, with 29 one-plant hills spaced $0.18 \mathrm{~m}$ apart, for a plant density of approximately 71,000 plants ha $^{-1}$. All the plots were manually harvested.

The following data were recorded on each plot: grain yield (kg ha-1 adjusted at $140 \mathrm{~g} \mathrm{H}_{2} \mathrm{O} \mathrm{kg}{ }^{-1}$ ), early vigor (number of leaves when plants were 31 days old), flowering (days from planting to $50 \%$ of the plants showing silks), plant height (in centimeters), total lodging (\%), and kernel moisture. Dates were recorded on the whole plot, except for plant height and kernel moisture, which were recorded on 10 plants and 10 ears per plot, respectively.

Combined analyses of variance were made using the adjusted means obtained from the lattice analysis of each environment if the effectiveness of the lattice design was above $105 \%$; otherwise, the agronomic traits were analyzed as randomized complete blocks. Environments were considered random and populations were considered fixed. The entry-by-environment mean squares, when significant, were used in tests of significance for differences among entries. The sums of squares due to genotypes were partitioned orthogonally for populations, population crosses, testcrosses, and hybrid checks. The populations were divided into effects due to populations from EZS33 [EZS33C0, EZS33(FR)C1, EZS33(FR)C2, and EZS33(FR)C3] and to populations from EZS34 [EZS34C0, EZS34(FR)C1, EZS34(FR)C2, and EZS34(FR)C3]. Linear and quadratic regression models were fit for entry means across environment on selection cycles for populations derived from EZS33 and EZS34, and for crosses between both populations to assess the response to selection. The mean square for each partition was tested with the mean square of the corresponding partition of the interaction (genotype $x$ environment) or experimental error. Means were compared by Fisher's protected LSD method (Steel et al., 1997). The sum of squares of testcrosses was divided into crosses defined as EZS33xB93, EZS33xEP42, EZS34xEZ6, and EZS34xEP42.

The evolution of heterosis in the breeding program was compared respect to difference between the mean of a cross and the average of the two parents (mid-parent heterosis) (Eyherabide and Hallauer, 1991). Genetic drift was measured for each population and cycle of selection, which let us know the genetic loss and the favorable alleles accumulated in the populations (Keeratinijakal and Lamkey, 1993). Data analyses were made using the SAS software package (SAS Institute, 2008).

\section{Results and discussion}

The combined analysis of variance across environments showed highly significant differences 
between genotypes for all agronomic traits, although the interactions between environment and genotypes were also significant (online source 1).

Populations and crosses between populations

For yield, the linear rate of response was significant $\left(0.25 \mathrm{Mg} \mathrm{ha}^{-1} \mathrm{cycle}^{-1}, 3.0 \% \mathrm{cycle}^{-1}\right)$ in the interpopulation crosses (Table 2).The linear response did not interact with environments (online source 1) indicating that the response was consistent; moreover, the lack of quadratic response suggests future possibilities of improvement (data not shown).The linear response obtained in our program was similar to the response obtained in several full sib RRS programs that reported a gain between 3 and 5\% per cycle (Menkir and Kling, 1999; Butruille et al., 2004; Moreno-Pérez et al., 2004; Ordás et al. 2012), although Eyherabide and Hallauer (1991) obtained a higher response $(7.5 \%$ cycle-1).

On the other hand, the linear response for yield was not significant in the populations per se (Table 2). Contrary to the positive and consistent response across experiment found in the interpopulation crosses, some authors reported a lack of response in both populations per se (Butruille et al., 2004; Moreno-Pérez et al., 2004), while other authors reported a positive response in one population (Romay et al. 2011; Ordas et al. 2012) or both (Eyherabide and Hallauer (1991). Romay et al. (2011) and Ordas et al. (2012) carried out a RRS program with one population adapted and other non-adapted to the environment where the selection was performed. In both RRS programs the positive response was achieved in the adapted population. In the RRS program of BS10 and BS11, carried out in the Corn Belt, BS10 can be considered more adapted than BS11, because BS10 was made primarily from Reid Yellow Dent germplasm, while BS11 included southern, non-adapted materials to the Corn Belt environment (Eyherabide and Hallauer, 1991). In this program, although both populations had a positive response, the response in the adapted population almost doubled the response in the nonadapted population (Eyherabide and Hallauer, 1991). In our program, although the response was not significant in the populations per se, a positive tendency was observed in the adapted population $(b=0.08)$, with a negative tendency in the non-adapted population $(b=-0.08)$. From ours and previous results, it seems that, when selection is performed in one adapted and one non-adapted population, full-sib RRS effectively improves the inter-population cross and tends to improve the adapted population.

Regarding the changes correlated with selection in the interpopulation cross, there was a significant linear reduction in flowering and plant height, while the kernel moisture and the lodging remained unchanged. Therefore, the increase of yield was not at expense of an increase in the maturity of the crop (Table 2). In most of the cases, the reduction in flowering days can be an advantage to escape from high temperatures and/or drought in the period more critical to the plants. However, the decreasing in plant height could reduce the interest of the interpopulation crosses for alternatively used as forage or biomass production. The selection for grain has not affected the stover yield in the US Corn Belt varieties; however the opposite situation occurred in tropical germplasm (Lorenz et al., 2010). Our results suggest that stover yield, or related traits, should be included in selection programs as selection criteria to prevent their decline. The early vigor of each cycle of selection was higher than the early vigor of the previous cycle in the interpopulation cross, although the linear rate of increase did not reach the significant level. The selection for yield probably had a weak effect on early vigor, but more cycles of selection are needed to detect a significant effect.

Regarding the correlated responses in the populations per se, EZS34 reduced flowering significantly and kernel moisture, while EZS33 did not. The changes in flowering time approach 
the values of EZS34 to the values of EZS33. This could be indicative of selection for adaptation in the non-adapted composite or, alternatively, the methodology of RRS, where crossing families of two composites could tend to approach the flowering dates of the populations. Similar results have been found in others experiments (Ruiz de Galarreta and Álvarez, 2007; populations, EZS33 and EZS34. The linear coefficient was significant in EZS33, but not in EZS34 although a linear tendency was also observed. The lodging of EZS33 (21\%) was higher than the lodging of EZS34 (11\%) in the original populations. This result was expected because EZS34was formed with four maize populations with a good resistance to borers, while EZS33 was formed with four adapted varieties, but never improved for lodging. One of the main agronomic disadvantages found in several local open-pollinated varieties is high lodging (Malvar et al., 1996; Carena and Wicks, 2006). The greatest reduction of lodging was reached in the first cycle, which is in agreement with Keeratinijakal and Lamkey (1993). On the other hand, Romay et al. (2011) observed this reduction in the third cycle. In general, we can resume that RRS has a good effect for decreasing lodging (Martin and Hallauer, 1980; Popi and Kannenberg, 2001).

\section{Heterosis and inbreeding}

Mid-parent heterosis for yield in the interpopulation crosses increased $0.26 \mathrm{Mg} \mathrm{ha}^{-1}$ cycle-1, but $^{-1}$ the linear tendency was not significant (Table 3). Others studies showed a significant linear coefficient of about $0.22 \mathrm{Mg} \mathrm{ha}^{-1} \mathrm{cycle}^{-1}$ after 11 cycles of selection (Keeratinijakal and Lamkey, 1993).

For the cycles C2 and C3 the yield of the populations per se was lower than the yield of the populations crossed to the original populations (Table 4). Furthermore, all the differences were significant, except for the cycle C3 of EZS33. This is most likely the result of inbreeding depression, which is present in the selected populations reducing their mean, but disappears when the improved populations are crossed with the original population (C0). This response is similar to the response reported by Rodriguez and Hallauer (1988), and Keeratinijakal and Lamkey (1993). Our data suggest that with 10 families selected per generation, a usual number in selection programs, fixation of deleterious alleles is probably happening as a consequence of random genetic drift. For that reason, to increase the frequency of the maximum number of favorable alleles in the long term, it would be worthwhile to increase the number of selected families at the expense of the response in the short term. This was made in the RRS of the BSSS and BSCB1 populations conducted by the Cooperative Federal-State maize breeding program in Iowa, in which the number of $S_{1}$ selected progenies was increased from 10 to 20 in order to reduce the cumulative effects of genetic drift (Keeratinijakal and Lamkey, 1993). The testcrosses of the cycles of selection of EZS33 and EZS34 to their original parents (cycle C0) linearly improved and worsened, respectively, their grain yield with selection (Table 4). This confirms the previous hypothesis that RRS effectively increases the frequency of favorable alleles for yield in the adapted population, although the inbreeding depression could counteract the effect of selection on the mean.

The early vigor (one trait related to adaptation) of the testcrosses of EZS34 (the non-adapted population) to cycle $\mathrm{C} 0$ changed linearly with selection, indicating that selection was effective increasing the frequency of favorable alleles. Thus, our results suggest that RRS for yield could be effective increasing the favorable alleles for adaptation of non-adapted germplasm.

\section{Crosses of cycles with testers}

For yield we found a significant $(\mathrm{P} \leq 0.05)$ linear response in the testcrosses of EZS33 and EZS34 
to all testers except $\mathrm{B} 93$, in which the linear response was significant at $\mathrm{P}=0.10$ (Table 2). These results suggest that RRS is able to improve not only the crosses between the reciprocal different heterotic groups. Thus, RRS can be useful to develop improved populations from which in turn it would be possible to develop lines with general and specific combining ability with other alternative heterotic groups. Therefore, RRS seems to be an appropriate methodology to make new germplasm available for elite breeding. The flowering time of most of the testcrosses was linearly reduced by RRS, which could be an advantage in order to escape from elevated temperatures in the more susceptible stage of the plant development.

On the other hand, the interpopulation crosses can be directly cultivated, mainly in agriculture of low inputs. We compared the yield of the improved population crosses with hybrid checks to assess the possibility of cultivation of interpopulation crosses (Table 2). We found that the yield of the population crosses in the third cycle of improvement did not differ significantly from the mean yield of the hybrid checks. These results confirm the hypothesis that some interpopulation crosses could produce similar yields than some hybrids in determinate conditions (Carena, 2005). We conclude that RRS could be an appropriate tool to develop improved interpopulation crosses for direct use by farmers.

\section{Conclusions}

Some useful genetic variability present in local varieties or synthetic populations is hampered by the poor agronomic performance of the populations, which prevents their use in elite breeding. Our results suggest that the RRS methodology is useful for improving non-elite varieties because efficiently improves grain yield, lodging, and adaptation of the populations. The use of heterotic patterns is widely spread in maize breeding and the RRS methodology allows the improvement of the specific combining ability of populations within a concrete heterotic pattern scheme. RRS also improves the general combining ability of populations, which gives more flexibility to the exploitation of the improved populations.

\section{Acknowledgments}

Research was supported by the Spanish plan of I+D (project AGL2010-22254). Javier Peña-Asin acknowledgesa fellowship from the Ministry of Science and Innovation of Spain.

\section{References}

Álvarez A, Garay G, Jiménez J, Ruíz de Galarreta JI (1993) Heterosis entre dos sintéticos de maíz expresado sobre caracteres morfológicos y reproductivos Investigación Agraria: Producción y Protección Vegetal 8:333-340.

Betrán FJ, Hallauer AR (1996) Hybrid improvement after reciprocal recurrent selection in BSSS and BSCB1 maize populations. Maydica 41:25-33.

Butruille DV, Silva HD, Kaeppler SM, Coors JG (2004) Response to selection and genetic drift in three populations derived from the Colden Clow maize population. Crop Sci 44:1527-1534.

Carena MJ (2005) Maize commercial hybrids compared to improved populations hybrids for grain yield and agronomic performance. Euphytica 141:201-208.

Carena MJ, Wicks ZW (2006) Maize population hybrids: an exploitation of US temperate public genetic diversity in reserve. Maydica 51:201-208. 
Eyherabide GH, Hallauer AR (1991) Reciprocal full-sib recurrent selection in maize: I Direct and indirect responses Crop Sci 31:952-959.

\section{FAOSTAT-FAO (2012) Statistical databases http://faostatfaoorg. Accesed2 Apr 2012}

Garay G, Igartua E, Álvarez A (1996a ) Responses to S1 Selection in Flint and Dent Synthetic Maize Populations. Crop Sci 36:1129-1134.

Garay G, Igartua E, Álvarez A (1996b) Combining ability associated with S1 Recurrent Selection in two maize synthetics. Maydica 41: 263-269.

Hallauer AR, Eberhart SA (1970) Reciprocal full-sib selection. Crop Sci 10: 315-316.

Ho JC, Kresovich S, Lamkey KR (2005) Extent and distribution of genetic variation in US maize: historically important lines and their open-pollinated dent and flint progenitors. Crop Sci 45:1891-1900.

Keeratinijakal V, Lamkey KR (1993) Responses to reciprocal recurrent selection in BSSS and BSCB1 maize populations. Crop Sci 33:73-77.

Lorenz AJ, Gustafson TJ, Coors JG, de Leon N (2010) Breeding maize for a bioeconomy: A literature survey examining harvest index and stover yield and their relationship to grain yield. Crop Sci 50: 1:1-12.

Malvar RA, Ordás A, Revilla P, Cartea ME (1996) Estimates of genetic variances in two Spanish populations of maize. Crop Sci 36: 291-295.

Malvar RA, Butrón A, Álvarez A, Ordás B, Soengas P, Revilla P, Ordás A (2004) Evaluation of the European Union Landraces core collection for resistance to Sesamia nonagrioides (Lepidoptera: Noctuidae) and Ostrinia nubilalis (Lepidoptera: Crambidae). J Econ Entomol 97:628-634.

Martin JM, Hallauer AR (1980) Seven cycles of reciprocal recurrent selection in BSSS and BSCB1 maize populations. Crop Sci20:599-603.

Menkir A, Kling JG (1999) Effect of reciprocal recurrent selection on grain yield and other traits in two early-maturing maize populations. Maydica 44:159-165.

Mikel MA (2011) Genetic composition of contemporary US commercial dent corn germplasm. Crop Sci 51:592-599.

Mikel MA, Dudley JW (2006) Evolution of North American dent maize from public to proprietary germplasm. Crop Sci 46:1193-1205.

Moreno-Perez ED, Lewis-Beck D, Cervantes-Santana T, Torres-Flores JI (2004) Reciprocal recurrent selection in Mexican Highland Valleys maize populations under high and low soil nitrogen content. Agrociencia 38:305-311.

Ordas B, Butrón A, Alvarez A, Revilla P, Malvar RA (2012) Comparison of two methods of reciprocal recurrent selection in maize (Zea mays L.). Theor Appl Genet 124:1183 -1191. 
Ordás A (1991) Heterosis in crosses between American and Spanish populations of maize. Crop Sci31:931-935.

Popi J, Kannenberg LW (2001) Response to selection over 15 years in the HOPE maize breeding system. Maydica 46:93-103.

Reif JC, Hallauer AR, Melchinger AE (2005) Heterosis and heterotic patterns in maize. Maydica 50:215-223.

Reif JC, Fischer S, Schrag TA, Lamkey KR, Klein D, Dhillon BS, Utz HF, Melchinger AE (2010) Broadening the genetic base of European maize heterotic pools with US Corn Belt germplasm using field and molecular marker Data. Theor Appl Genet 120:301-310.

Revilla P, Boyat A, Álvarez A, Gouesnard B, Ordás B, Rodríguez VM, Ordás A, Malvar RA (2006) Contribution of autochthonous maize populations for adaptation to European conditions. Euphytica 152:275-282.

Rodriguez OA, Hallauer AR (1988) Effects of recurrent selection in maize populations. Crop Sci 28:796-800.

Romay MC, Ordás B, Revilla P, Ordás A (2011) Three cycles of full-sib reciprocal recurrent selection in two Spanish maize populations. Crop Sci 51:1016-1022.

Ruiz de Galarreta JI, Álvarez A (2007) Six cycles of S1 recurrent selection in two Spanish maize synthetics. Span J Agric Res 5:193-198.

SAS Institute (2008) The SAS system for Windows Release 9.2 SAS Institute Inc, Cary NC, USA.

Soengas P, Ordás B, Malvar RA, Revilla P, Ordás A (2003) Heterotic patterns among flint maize populations. Crop Sci 43:844-849.

Steel RGD, Torrie JH, Dickey DA (1997) Principles and procedures of statistics: biometrical approach. 3rded McGraw-Hill, USA.

Yu J, Bernardo R (2004) Changes in genetic variance during advanced cycle breeding in maize. Crop Sci 44:405-410. 
Table 1: Populations of maize used in this study, all crosses between them, the testcrosses of the cycles of selection to two inbred lines, and the hybrid checks, grown at five environments in 2009 and 2010 in Spain.

\begin{tabular}{|l|l|}
\hline per se populations & EZS33C1 $\times$ EP42 \\
EZS33C0 & EZS33C2 $\times$ B93 \\
EZS33C1 & EZS33C2 $\times$ EP42 \\
EZS33C2 & EZS33C3 $\times$ B93 \\
EZS33C3 & EZS33C3 $\times$ EP42 \\
EZS34C0 & EZS34C0 $\times$ EZ6 \\
EZS34C1 & EZS34C0 $\times$ EP42 \\
EZS34C2 & EZS34C1 $\times$ EZ6 \\
EZS34C3 & EZS34C1 $\times$ EP42 \\
\hline Intervarietal crosses & EZS34C2 $\times$ EZ6 \\
EZS34C0 $\times$ EZS33C0 & EZS34C2 $\times$ EP42 \\
EZS34C1 $\times$ EZS33C1 & EZS34C3 $\times$ EZ6 \\
EZS34C2 $\times$ EZS33C2 & EZS34C3 $\times$ EP42 \\
EZS34C3 $\times$ EZS33C3 & Hybrids checks \\
\hline Testcrosses & B73 $\times$ Mo17 \\
EZS33C0 $\times$ B93 & COSTANZA \\
EZS33C0 $\times$ EP42 & DRACMA \\
EZS33C1 x B93 & HELEN \\
\cline { 2 - 2 }
\end{tabular}


Table 2: Means for yield and some agronomic traits for the cycles (C0-C3) of the EZS33 and EZS34 population of maize, all crosses between them, the testcrosses of the cycles of selection to two inbred lines, and the hybrid checks, grown at five environments in 2009 and 2010 in Spain. The regression coefficients of each character on cycles of selection are also shown

\begin{tabular}{|c|c|c|c|c|c|c|}
\hline Material & $\begin{array}{l}\text { Grain } \\
\text { yield }\end{array}$ & $\begin{array}{l}\text { Total } \\
\text { lodging }\end{array}$ & $\begin{array}{l}\text { Early } \\
\text { vigor }\end{array}$ & Flowering & $\begin{array}{l}\text { Kernel } \\
\text { moisture }\end{array}$ & $\begin{array}{l}\text { Plant } \\
\text { height }\end{array}$ \\
\hline \multirow[b]{2}{*}{ Populations } & $M g h a^{-1}$ & $\%$ & leaves & Days & $\%$ & $\mathrm{~cm}$ \\
\hline & & & & & & \\
\hline EZS33C0 & 6.17 & 20.8 & 7.5 & 72.6 & 20.0 & 176 \\
\hline EZS33C1 & 6.25 & 19.0 & 7.3 & 72.8 & 21.1 & 174 \\
\hline EZS33C2 & 6.05 & 17.5 & 7.4 & 72.3 & 19.9 & 166 \\
\hline EZS33C3 & 6.51 & 16.2 & 7.3 & 71.9 & 18.6 & 166 \\
\hline Regression coefficient $(b)^{a}$ & 0.08 & $-1.52^{* *}$ & -0.03 & -0.26 & -0.48 & $-3.7^{* *}$ \\
\hline EZS34C0 & 6.01 & 10.8 & 7.3 & 77.8 & 20.3 & 198 \\
\hline EZS34C1 & 7.06 & 8.7 & 7.3 & 76.4 & 19.6 & 182 \\
\hline EZS34C2 & 6.72 & 7.6 & 7.5 & 75.3 & 18.7 & 169 \\
\hline EZS34C3 & 5.85 & 7.7 & 7.3 & 74.8 & 18.9 & 167 \\
\hline Regression coefficient $(b)^{a}$ & -0.08 & -1.04 & 0.03 & $-1.01^{* *}$ & $-0.50^{* *}$ & $-10.6^{* *}$ \\
\hline $\operatorname{LSD}(5 \%)$ & 0.45 & 10.5 & $n s^{b}$ & 1.8 & 1.64 & 62 \\
\hline \multicolumn{7}{|l|}{ Crosses } \\
\hline EZS34C0xEZS33C0 & 8.25 & 13.4 & 7.4 & 74.7 & 19.9 & 208 \\
\hline EZS34C1xEZS33C1 & 8.73 & 18.8 & 7.6 & 73.0 & 19.7 & 200 \\
\hline EZS34C2xEZS33C2 & 8.60 & 12.6 & 7.7 & 73.3 & 19.8 & 187 \\
\hline EZS34C3xEZS33C3 & 9.11 & 12.3 & 7.8 & 72.5 & 20.2 & 180 \\
\hline Regression coefficient $(b)^{a}$ & $0.25^{* *}$ & -0.94 & 0.13 & $-0.59^{* *}$ & 0.08 & $-9.5^{* *}$ \\
\hline $\operatorname{LSD}(5 \%)$ & 0.79 & 10.5 & 0.07 & 1.43 & 1.09 & 40 \\
\hline \multicolumn{7}{|l|}{ TestCrosses } \\
\hline EZS33C0xB93 & 8.83 & 12.9 & 7.8 & 72.1 & 19.4 & 183 \\
\hline EZS33C1xB93 & 9.95 & 16.5 & 7.6 & 71.5 & 21.4 & 185 \\
\hline EZS33C2xB93 & 9.29 & 14.7 & 7.7 & 72.7 & 21.6 & 175 \\
\hline EZS33C3xB93 & 9.79 & 14.9 & 7.7 & 71.5 & 20.1 & 178 \\
\hline Regression coefficient (b)a & 0.22 & 0.42 & 0.00 & -0.07 & 0.22 & -2.55 \\
\hline EZS33C0xEP42 & 7.33 & 17.0 & 7.4 & 68.8 & 16.3 & 179 \\
\hline EZS33C1xEP42 & 7.33 & 18.6 & 7.6 & 67.1 & 16.4 & 168 \\
\hline EZS33C2xEP42 & 8.53 & 13.5 & 7.8 & 67.3 & 15.8 & 166 \\
\hline EZS33C3xEP42 & 8.07 & 10.4 & 7.9 & 67.6 & 16.8 & 174 \\
\hline Regression coefficient $(b)^{a}$ & $0.34^{* *}$ & $-2.48^{* *}$ & $0.16^{* *}$ & $-0.33^{*}$ & 0.09 & -1.57 \\
\hline EZS34C0xEZ6 & 8.57 & 10.2 & 8.0 & 74.3 & 18.2 & 200 \\
\hline EZS34C1xEZ6 & 9.52 & 11.0 & 8.1 & 73.2 & 17.9 & 198 \\
\hline EZS34C2xEZ6 & 9.60 & 9.5 & 8.0 & 73.5 & 18.3 & 192 \\
\hline EZS34C3xEZ6 & 9.63 & 11.1 & 8.2 & 72.2 & 17.1 & 196 \\
\hline Regression coefficient $(b)^{a}$ & $0.32^{* *}$ & 0.11 & 0.05 & $-0.61^{* *}$ & -0.28 & -1.74 \\
\hline EZS34C0xEP42 & 8.45 & 10.4 & 7.6 & 71.7 & 16.1 & 187 \\
\hline EZS34C1xEP42 & 8.38 & 10.8 & 7.8 & 68.7 & 15.9 & 185 \\
\hline EZS34C2xEP42 & 8.25 & 9.5 & 7.6 & 67.9 & 15.3 & 178 \\
\hline EZS34C3xEP42 & 9.25 & 11.5 & 7.9 & 69.4 & 15.6 & 180 \\
\hline Regression coefficient (b)a & $0.28^{*}$ & 0.21 & 0.07 & $-0.76^{* *}$ & -0.21 & -2.9 \\
\hline $\operatorname{LSD}(5 \%)$ & 1.22 & 10.5 & 0.07 & 1.43 & 1.24 & 42 \\
\hline $\begin{array}{l}\text { Hybrids checks } \\
\text { B73×Mo18 }\end{array}$ & 7.48 & 12.9 & 6.9 & 79.3 & 23.2 & 198 \\
\hline
\end{tabular}




\begin{tabular}{l|llllll}
\hline COSTANZA & 10.83 & 4.0 & 6.7 & 78.4 & 19.0 & 197 \\
DRACMA & 9.41 & 4.3 & 6.9 & 78.3 & 20.2 & 189 \\
HELEN & 10.80 & 3.5 & 6.4 & 77.3 & 19.7 & 213 \\
LSD $(5 \%)$ & 1.96 & 10.5 & $n s^{b}$ & 0.90 & 1.94 & 27 \\
\hline
\end{tabular}

athe significance of the regression coefficients were tested with an analysis of variance (online source 1) ${ }^{b} n s$ : the differences between the means were not significant according to the analysis of variance (online source 1) 
Table 3: Mid-parent heterosis for yield and some agronomic traits exhibited by the crosses of the EZS33 and EZS34 populations of maize evaluated in five environments in 2009 and 2010 in Spain. The regression coefficients of mid-parent heterosis on cycles of selection are also shown

\begin{tabular}{|c|c|c|c|c|c|c|}
\hline Material & $\begin{array}{l}\text { Grain } \\
\text { yield }\end{array}$ & $\begin{array}{l}\text { Total } \\
\text { lodging }\end{array}$ & $\begin{array}{l}\text { Early } \\
\text { vigor }\end{array}$ & Flowering & $\begin{array}{l}\text { Kernel } \\
\text { moisture }\end{array}$ & $\begin{array}{l}\text { Plant } \\
\text { height }\end{array}$ \\
\hline \multirow[b]{2}{*}{ Cycle of selection } & $M g h a^{-1}$ & $\%$ & leaves & Days & $\%$ & $\mathrm{~cm}$ \\
\hline & \multicolumn{6}{|c|}{$\underline{\text { Mid-parent heterosis }}$} \\
\hline EZS34C0 x EZS33C0 & $2.15^{* *}$ & -2.4 & -0.0 & -0.6 & -0.2 & $16.4^{* *}$ \\
\hline EZS34C1 x EZS33C1 & $2.07^{* *}$ & $4.9^{* *}$ & $0.3^{*}$ & $-1.7^{* *}$ & -0.7 & $17.9^{* *}$ \\
\hline $\mathrm{EZS} 34 \mathrm{C} 2 \times \mathrm{EZS} 33 \mathrm{C} 2$ & $2.22^{* *}$ & 0.0 & $0.2^{*}$ & -0.5 & 0.4 & $16.1^{* *}$ \\
\hline EZS34C3 x EZS33C3 & $2.93^{*}$ & 0.3 & 0.4 & -0.8 & $1.4^{* *}$ & $10.7^{* *}$ \\
\hline Regression coefficient $(b)^{a}$ & 0.25 & 0.33 & $0.13^{*}$ & 0.04 & $0.58^{* *}$ & -1.89 \\
\hline
\end{tabular}

*** significant at the 0.05 and 0.01 probability level respectively

athe significance of the regression coefficients were tested with an analysis of variance (online source 2)

${ }^{b}$ Evaluation of the EZS34xEZZS33 cross against the best parent 
Table 4: Means of yield and some agronomic traits for the improved cycles (C1-C3) of the EZS33 and EZS34 population of maize crossed to the original cycles (C0) and differences between the cycles per se and crossed to $\mathrm{C} 0$. The regression coefficients of each character on the cycles of selection are also shown for the improved cycles crossed to C0.All populations were evaluated in five environments in 2009 and 2010 in Spain.

\begin{tabular}{l|llllll}
\hline Material & $\begin{array}{l}\text { Grain } \\
\text { yield }\end{array}$ & $\begin{array}{l}\text { Total } \\
\text { lodging }\end{array}$ & $\begin{array}{l}\text { Early } \\
\text { vigor }\end{array}$ & Flowering & $\begin{array}{l}\text { Kernel } \\
\text { moisture }\end{array}$ & $\begin{array}{l}\text { Plant } \\
\text { height }\end{array}$ \\
\hline Cycle of selection & $M g$ ha $^{-1}$ & $\%$ & leaves & Days & $\%$ & cm \\
\cline { 2 - 7 } EZS33C1 x EZS33C0 & 6.10 & 23.2 & 7.6 & 71.7 & 20.6 & 182 \\
EZS33C1 vs (EZS33C1xEZS33C0) & 0.1 & -4.2 & -0.3 & 1.2 & 0.5 & $-6^{*}$ \\
EZS33C2 x EZS33C0 & 7.14 & 27.7 & 7.5 & 72.5 & 19.6 & 176 \\
EZS33C2 vs(EZS33C2xEZS33C0) & $-1.1^{* *}$ & $-10.2^{* *}$ & -0.1 & -0.1 & 0.3 & $-8^{* *}$ \\
EZS33C3 x EZS33C0 & 6.72 & 16.8 & 7.7 & 73.2 & 20.9 & 176 \\
EZS33C3 vs(EZS33C3xEZS33C0) & -0.2 & -0.5 & $-0.3^{*}$ & $-1.3^{*}$ & $-2.2^{* *}$ & $-7^{* *}$ \\
Regression coefficient (b) & $0.31^{* *}$ & -3.20 & 0.08 & $0.76^{* *}$ & 0.14 & -3.00 \\
& & & & & & \\
EZS34C1 x EZS34C0 & 7.35 & 14.7 & 7.5 & 75.4 & 20.4 & 191 \\
EZS34C1 vs(EZS34C1xEZS34C0) & -0.3 & $-6.0^{* *}$ & -0.1 & 1.0 & -0.7 & $-7^{* *}$ \\
EZS34C2 x EZS34C0 & 8.00 & 9.9 & 7.6 & 74.7 & 18.4 & 193 \\
EZS34C2 vs(EZS34C2xEZS34C0) & $-1.3^{* *}$ & -2.3 & -0.0 & 0.6 & 0.4 & $-20^{* *}$ \\
EZS34C3 x EZS34C0 & 6.86 & 8.7 & 7.6 & 75.4 & 19.6 & 185 \\
EZS34C3 vs(EZS34C3xEZS34C0) & $-1.0^{* *}$ & -1.0 & -0.2 & -0.6 & -0.6 & $-14^{*}$ \\
Regression coefficient (b) ${ }^{*}$ & $-0.24^{* *}$ & -3.00 & $0.06^{* *}$ & -0.00 & -0.37 & -0.24 \\
\hline *** significant at the 0.05 and 0.01 probability level respectively & & & \\
athe significance of the regression coefficients were tested with an analysis of variance (online source 3)
\end{tabular}

